\title{
Hsp90 inhibitor, BIIB021, induces apoptosis and autophagy by regulating mTOR-Ulk1 pathway in imatinib-sensitive and -resistant chronic myeloid leukemia cells
}

\author{
WEI HE ${ }^{1 *}$, XIUJIN YE ${ }^{1 *}$, XIANBO HUANG ${ }^{1}$, WEN LEL ${ }^{1}$, LIANGSHUN YOU $^{1}$, \\ LEI WANG ${ }^{1}$, XIAOHUI CHEN ${ }^{2}$ and WENBIN QIAN ${ }^{1}$ \\ ${ }^{1}$ Institute of Hematology, The First Affiliated Hospital, College of Medicine, Zhejiang University; \\ ${ }^{2}$ Department of Hematology, The Affiliated Hospital of Hangzhou Normal University, Hangzhou, Zhejiang, P.R. China
}

Received December 1, 2015; Accepted January 22, 2016

DOI: $10.3892 / \mathrm{ijo} .2016 .3382$

\begin{abstract}
Development of drug resistance due to BCR-ABL point mutations and the persistence of leukemia initiating cells has become a major obstacle for tyrosine kinase inhibitors (TKIs) in the treatment of chronic myeloid leukemia (CML). The BCR-ABL protein is an important client protein of heat shock protein 90 (Hsp90). BIIB021, an orally available Hsp90 inhibitor, has activity against various cancer cells. However, little is known about the inhibitory effect of BIIB021 on CML cells. We evaluated the inhibitory effects of BIIB021 on $\mathrm{K} 562$, K562/G (an imatinib-resistant cell lines), as well as 32D mouse leukemic cells expressing wild-type BCR-ABL (b3a2, 32Dp210) and T315I mutant BCR-ABL (32Dp210T315I) cells. Our data showed that BIIB021 induced significant growth inhibition and apoptosis that was predominantly mediated by the mitochondrial pathway. BIIB021 also resulted in proteasomal degradation of BCR-ABL proteins. In addition to induction of apoptosis, we report for the first time that BIIB021 induced autophagic response as evidenced by the formation of autophagosome, increased conversion of microtubuleassociated protein light chain 3 (LC3)-I to LC3-II, decreased p62 (SQSTM1) protein levels. Further study suggested that Akt-mTOR-Ulk1 signaling pathway was involved in BIIB021triggered autophagy. Moreover, blocking autophagy using pharmacological inhibitor 3-methyladenine and bafilomycin A1 significantly enhanced cell death and apoptosis induced by BIIB021, indicating the cytoprotective role of autophagy in BIIB021-treated CML cells. Collectively, these data provide possible molecular mechanisms for the antileukemic effect of
\end{abstract}

Correspondence to: Professor Wenbin Qian, Department of Hematology, The First Affiliated Hospital, Zhejiang University, 79 Qingchun Road, Hangzhou, Zhejiang 310003, P.R. China E-mail: qianwenb@hotmail.com

\section{${ }^{*}$ Contributed equally}

Key words: BIIB021, chronic myeloid leukemia, autophagy, BCR-ABL, mTOR, Ulk1
BIIB021 on imatinib-sensitive and -resistant CML cells and provide new insights into the future application of BIIB021 in the clinical treatment of CML.

\section{Introduction}

Chronic myeloid leukemia (CML) is a myeloproliferative disorder characterized by the BCR-ABL gene rearrangement $(1,2)$. As a driving force for leukemogenesis of CML, the activated tyrosine kinase of BCR-ABL stimulates multiple signaling pathways that confers growth advantage and counteracts apoptosis (3-5). The most prominent downstream pathways upregulated by BCR-ABL include the Ras/ Raf/MAPK, PI3K/Akt, and JAK/STAT pathways. Imatinib mesylate, a selective BCR-ABL tyrosine kinase inhibitor (TKI), has become the standard therapy in CML. It induces durable cytogenetic remissions in the majority of chronicphase patients with CML, but a significant proportion of the patients experiences drug-resistance, mainly as a consequence of BCR-ABL point mutations (6). Among BCR-ABL point mutations, T315I mutant remains a crucial clinical challenge, because it is resistant to imatinib and second generation TKIs $(7,8)$. Ponatinib, a third-generation TKI, has an antileukemia activity against CML with unmutated or mutated BCR-ABL including T315I. However, its use clinically is limited by serious side effects such as vascular occlusion, heart failure and hepatotoxicity $(9,10)$.

As an ATP-dependent molecule chaperon, heat shock protein 90 (Hsp90) is associated with many different client oncoproteins such as BCR-ABL, Raf, ErbB and Akt (11). Disruption of Hsp90 function by specific inhibitors leads to the destabilization and degradation of its client oncoproteins, thereby inhibiting cell growth and inducing apoptosis in cancer cells (12). Thus, Hsp90 represents a promising molecular target for cancer therapy. In this regard, it was demonstrated that a prototypical Hsp90 inhibitor geldanamycin and its analogue 17-AAG downregulated BCR-ABL levels and induced apoptosis of CML cells (13). Similar results have been obtained with some synthetic Hsp90 inhibitors such as AUY922A and EC141 (14-16) suggesting that targeting Hsp90 might be a promising therapeutic approach to treat CML. 
BIIB021, the first fully synthetic inhibitor, has a high binding affinity for Hsp90, and induces degradation of Hsp90 client proteins including HER-2, Akt and Raf-1 (17). It was reported that BIIB021 was more active than 17-AAG against tumor cells with acquired multidrug resistance (18). Preclinical data have also demonstrated the potent anticancer activity in various solid tumors and hematological malignancies (18-20). In a phase I clinical trial performed in patients with advanced solid tumors, BIIB021 safety profile was displayed and a phase II study documented objective responses in refractory gastrointestinal stromal tumor patients $(21,22)$. We recently reported that BIIB021 mediates its antileukemic activity via inhibiting PI3K/Akt pathway and disrupting p53-MDM2 interaction $(23,24)$. These results indicated the multiple biological functions of BIIB021. However, little is known about the effects of BIIB021 on CML cells.

In this study, we investigated the biological effects of BIIB021 on CML cells. We found that BIIB021 induces potent cytotoxicity against imatinib-sensitive and -resistant CML cells as well as leukemic cells with T315I-mutant BCR-ABL. BIIB021 also induces proteasomal degradation of BCR-ABL. Interestingly, treatment with BIIB021 results in a cytoprotective autophagy, which might be independent of Beclin-1 but dependent on mTOR-Ulk1 pathway.

\section{Materials and methods}

Cell culture and reagents. Human CML cell line K562 was obtained from American Type Culture Collection (ATCC, Rockville, MD, USA). K562/G, an imatinib-resistant cell line, was kindly provided by Institute of Hematology, Chinese Academy of Medical Sciences (Tianjin, China). Murine leukemic 32D cells with wild-type (wt) BCR-ABL (32Dp210) and 32Dp210-T315I (32D cells carrying T315I mutation) were provided by Professir L. Qiu (Harbin Institute of Hematology and Oncology, Harbin, China). All cell lines were cultured in RPMI-1640 medium (Gibco-RRL, Grand Island, NY, USA) supplemented with $10 \%$ fetal bovine serum (Gibco) at $37^{\circ} \mathrm{C}$ in a humidified atmosphere of 5\% $\mathrm{CO}_{2}$. BIIB021, MG-132, 3-methyladenine (3-MA), z-DEVD-fmk and z-VAD-fmk were purchased from Selleck Chemicals (Houston, TX, USA). Insulin-like growth factor 1 (IGF-1) was purchased from Peprotech (Rocky Hill, NJ, USA). Bafilomycin A1 (Baf A1) was obtained from LC Laboratories (Woburn, MA, USA). Chloroquine (CQ) and 3-(4,5-dimethylthiazol-2-yl)2,5-diphenyltetrazolium bromide (MTT) were purchased from Sigma-Aldrich (St. Louis, MO, USA). All antibodies used in the western blot analysis were purchased from Cell Signaling Technology (Beverly, MA, USA) with the exception of p-STAT3 Ser727, p-STAT3 Tyr705, Ulk1 (Abcam, Cambridge, UK) and Lamin B1 (Proteintech, Chicago, IL, USA).

Cell viability assays. The survival of CML cells was determined by means of the MTT assay. Cells were cultured at a density of $1 \times 10^{5}$ cells $/ \mathrm{ml}$ in a 96-well plate with BIIB021 (50-800 nM) for the indicated times. Following incubation, $20 \mu \mathrm{l} \mathrm{MTT}$ solutions $(5 \mathrm{mg} / \mathrm{ml})$ were added to each well and then the plates were incubated for an additional $4 \mathrm{~h}$ at $37^{\circ} \mathrm{C}$. After supernatant was removed, $200 \mu 1$ dimethylsulfoxide (DMSO) was added. A spectrophotometry was applied to detect the absorbance at a wavelength of $570 \mathrm{~nm}$. Each assay was performed three times.

Annexin V/PI binding assays. Cells were cultured at a density of $1 \times 10^{5}$ cells $/ \mathrm{ml}$ in a 6 -well plate and treated with different concentrations of BIIB021. After 48 -h incubation at $37^{\circ} \mathrm{C}$, the cells were washed, resuspended in $500 \mu \mathrm{l}$ of binding buffer and stained with $5 \mu \mathrm{l}$ of Annexin V-FITC and $10 \mu \mathrm{l}$ of propidium iodide (PI) (Biouniquer, Suzhou, China) for $15 \mathrm{~min}$ in the dark. Then cells were examined by flow cytometry (Accuri C6, BD, Franklin Lakes, NJ, USA).

Real-time PCR. Total RNA was isolated and quantitative realtime PCR was performed as previously described (25) using the primers (Sangon Biotech, Shanghai, China): 5'-TCC GCT GAC CAT CAA YAA GGA-3' (forward) and 5'-CAC TCA GAC CCT GAG GCT CAA-3' (reverse) for p210BCR-ABL and 5'-GTC ATC ACC ATT GGC AAT GAG-3' (forward) and 5'-CGT CAC ACT TCA TGA TGG AGT T-3' (reverse) for GAPDH. The amount of p210BCR-ABL was analyzed by the comparative CT method taking GAPDH as the control.

Western blot analysis. Following treatment at the indicated time and doses of BIIB021, cells were collected and lysed at $4^{\circ} \mathrm{C}$ in lysis buffer. Protein concentration of samples was measured by bicinchoninic acid (BCA) method. The protein samples were separated by sodium dodecyl sulfate-polyacrylamide gel electrophoresis and then electroblotted onto hybond-polyvinylidene fluoride membranes. The membranes were blocked in $5 \%$ non-fat milk for $2 \mathrm{~h}$ and incubated with primary antibodies at $4^{\circ} \mathrm{C}$ overnight. The membranes were washed and incubated with secondary antibody conjugated with horseradish peroxidase (1:5,000, Cell Signaling Technology). ECL detecting kit was applied to visualize results. The primary antibodies used in this study included actin, caspase-9, caspase-3, poly(ADP ribose) polymerase (PARP), Bcl-2, Bax, Bak, Bad, Mcl-1, Bcl-XL, c-ABL, p-BCR Tyr177, JAK2, STAT5, p-STAT5 Tyr694, STAT3, p-STAT3 Ser727, p-STAT3 Tyr705, EKR1/2, p-EKR1/2 Thr202/Tyr204, Akt, $\beta$-catenin, non-phospho- $\beta$ catenin (Ser33/37/Thr41), c-Myc, Lamin B1, LC3I/II, p62, Beclin-1, mTOR, p-mTOR Ser2448, p70S6K, p-p70S6K Thr389, Ulk1, p-Ulk1 Ser757, AMPKa, p-AMPK $\alpha$ Thr172.

Preparation of cytoplasm and nuclear fractions. The cytoplasm and nuclear proteins were extracted using NE-PER Nuclear and Cytoplasmic Extraction Reagents (Thermo Fisher Scientific, Rockford, IL, USA) according to the manufacturer's instructions. BIIB021-treated cells were pelleted by centrifugation and rinsed with PBS. Then, cells were suspended in ice-cold Cytoplasmic Extraction Reagent I, and the tube was vortexed for $15 \mathrm{sec}$. After incubation on ice for $10 \mathrm{~min}$, the tube was added in Cytoplasmic Extraction Reagent II, vortexed, incubated and centrifuged at $16,000 \mathrm{~g}$ for $5 \mathrm{~min}$. The supernatant was transferred to a fresh tube and referred to as cytoplasm extract. The insoluble fraction, containing nuclei, was suspended in ice-cold nuclear extraction reagent, placed on ice and continued vortexing for $15 \mathrm{sec}$ every $10 \mathrm{~min}$, for a total of $40 \mathrm{~min}$. After centrifugation at $16,000 \mathrm{~g}$ for $10 \mathrm{~min}$, the supernatant was transferred to a new tube and kept as nuclear fraction. 
Detection of acidic vesicular organelles. To detect the presence of acidic vesicular organelles (AVOs), cells were treated with BIIB021 for $48 \mathrm{~h}$. Next, cells were stained with acridine orange (AO $1 \mu \mathrm{g} / \mathrm{ml}, 37^{\circ} \mathrm{C}$ for $15 \mathrm{~min}$, Sigma) or monodansylcadaverine (MDC, $0.1 \mathrm{mM}, 37^{\circ} \mathrm{C}$ for $60 \mathrm{~min}$, Sigma), fixed with $4 \%$ paraformaldehyde and examined under a fluorescence microscope (Olympus, Tokyo, Japan).

Immunofluorescence studies. Cells were treated with or without BIIB021 for $24 \mathrm{~h}$ and then fixed with $4 \%$ paraformaldehyde. After permeablized by $0.3 \%$ Triton X-100 and incubated with goat serum, cells were stained with anti$\beta$-catenin antibody (Abcam, 1:200 dilution) overnight at $4^{\circ} \mathrm{C}$. Then, cells were incubated with a goat anti-rabbit antibody as secondary antibody $(1: 500)$ at $37^{\circ} \mathrm{C}$ for $1 \mathrm{~h}$ and $1 \mu \mathrm{M}$ DAPI (SouthernBiotech, Birmingham, AL, USA) for $10 \mathrm{~min}$. Finally, samples were examined with a Nikon confocal microscope (Nikon C1-Si, Japan).

Approximately $10^{5}$ cells were treated with or without BIIB021 for $24 \mathrm{~h}$. After washing with PBS, cells were incubated with MitoTracker (Invitrogen, Carlsbad, CA, USA) at a concentration of $100 \mathrm{nM}\left(37^{\circ} \mathrm{C}\right.$ for $\left.0.5 \mathrm{~h}\right)$ to visualize mitochondria. Then cells were fixed with $4 \%$ paraformaldehyde and following experiments were performed as described above except the primary antibody (cytochrome $c$, Abcam, 1:200 dilution) and secondary antibody (goat anti-mouse antibody, 1:500).

Staining autophagosomes with mRFP-GFP-LC3 and confocal microscopy. To detect the presence of LC3, leukemia cells were transfected with adenovirus encoding red and green fluorescent protein-LC3 (AdmRFP-GFP-LC3) at a concentration of 800 virus particles/cell. After centrifugation at $500 \mathrm{~g}$ for $1 \mathrm{~h}$ and incubation for $3 \mathrm{~h}$ at $37^{\circ} \mathrm{C}$, cells were exposed to BIIB021 for $48 \mathrm{~h}$. Cells were fixed with $4 \%$ paraformaldehyde. The fluorescence of mRFP-GFP-LC3 was viewed under a confocal microscope (Nikon C1-Si, Japan).

Caspase-3 knockdown by short hairpin RNA. Three lentiviral vectors containing shRNA against caspase- 3 and a negative control scramble shRNA were purchased from Hanheng Biotech (Shanghai, China). K562 cells ( $2 \times 10^{4}$ cells/well) were seeded in a 96-well plate and transfected with lentivirus at a concentration of 100 virus particles/cell. After centrifugation at $800 \mathrm{~g}$ for $1 \mathrm{~h}$, cells were cultured at $37^{\circ} \mathrm{C}$. Then cells were selected in medium containing puromycin $(2 \mu \mathrm{g} / \mathrm{ml})$. Protein expression of caspase-3 was determined by western blot analysis. The sequence of shRNA targeting caspase- 3 was 5'-GGAAGCGAATCAATGGACTCTGGAA-3'.

Statistical analysis. Experimental results are statistically presented as the mean \pm standard deviation. Data were analyzed by one-way analysis of variance. $\mathrm{P}<0.05$ was considered to indicate a statistically significant difference.

\section{Results}

BIIB021 inhibits proliferation and induces apoptosis in both imatinib-sensitive and-resistant CML cells. To investigate the effects of BIIB021 on the cellular proliferation of CML cells, human CML cell lines K562, K562/G and a pair of murine 32D leukemic cell lines 32Dp210, and 32Dp210T315I were treated with different concentrations of BIIB021 for 24,48 or $72 \mathrm{~h}$, respectively. An MTT assay was used to determine the cell viability. The results showed that BIIB021 effectively inhibited the proliferation of CML cell lines in a dose- and time-dependent manner. The $50 \%$ inhibition $\left(\mathrm{IC}_{50}\right)$ of BIIB021 in K562, K562/G, 32Dp210, and 32Dp210-T315I cell lines at $48 \mathrm{~h}$ was observed at 513.99, 603.53, 110.08 and $148.07 \mathrm{nM}$, respectively (Fig. 1A). In order to characterize the cytotoxicity of BIIB021 against CML cells, we next performed Annexin V apoptosis assays in K562, K562/G, 32Dp210, and 32Dp210-T316I cells treated with multiple doses of BIIB021 for $48 \mathrm{~h}$. Treatment with the drug resulted in a marked increase in the number of early (Annexin V-positive/PI-negative) and late apoptotic (Annexin V-positive/PI-positive) cells at 100 and $200 \mathrm{nM}$ concentrations (Fig. 1B). We further tested molecules that control apoptosis. Western blot analysis was used to confirm our flow cytometric findings by showing that BIIB021 treatment activated key molecules in the apoptosis pathway, namely, caspase-9, -3 and PARP (Fig. 1C).

Based on the observation of activation of caspase-9, we monitored the release of cytochrome $c$ from mitochondria in K562 cells after treatment with BIIB021 (400 nM) by confocal microscopy. A significant increase was observed in cytochrome $c$ released from dsRed Mitotracker-tagged mitochondria (Fig. 2A). Furthermore, western blot analysis revealed that BIIB021 treatment resulted in upregulation of pro-apoptotic protein Bak and Bad, which are associated with the function of mitochondria, while anti-apoptotic protein Mcl-1 was downregulated (Fig. 2B). Taken together, these findings suggested that the mitochondria-dependent intrinsic apoptotic pathway is involved in BIIB021-induced cell death.

BIIB021 effectively inhibits BCR-ABL and its downstream molecules. It has been shown that rapid degradation of BCR-ABL protein could be observed in the leukemic cells treated with Hsp90 inhibitors (16). In this study we observed a dose-dependent inhibition of BCR-ABL protein when the CML cell lines, which express wild-type or T315I BCR-ABL, were treated with BIIB021, and that the depletion of BCR-ABL protein was accompanied by a concomitant decrease in phosphorylation of BCR-ABL protein on Tyr177 (Fig. 3A). To investigate how the agent alters BCR-ABL expression, we examined mRNA expression levels of BCR-ABL in response to BIIB021 (Fig. 3B). The results showed that the BCR-ABL mRNA level slightly increased, suggesting BIIB021 acts on BCR-ABL expression at the post-transcriptional level. Indeed, BIIB021-mediated downregulation of BCR-ABL was partly reversed by MG-132, a proteasome inhibitor, whereas CQ, a lysosome inhibitor, and Baf A1 did not show a similar effect (Fig. 3C and D). These findings suggested that proteasome pathway is involved in the BIIB021-mediated downregulation of BCR-ABL. We next evaluated the effects of BIIB021 on downstream pathways, which are stimulated by BCR-ABL (3-5). Treatment with BIIB021 clearly decreased the phosphorylation of STAT3, STAT5 and ERK1/2. Additionally, BIIB021 induced downregulation of total levels of JAK2 and Akt (Fig. 3E). Taken together, we demonstrated that BIIB021 effectively inhibits the protein expression of BCR-ABL and its downstream signaling mediators. 
A

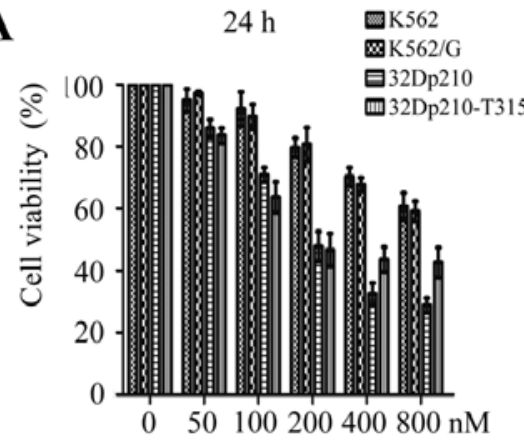

$48 \mathrm{~h}$

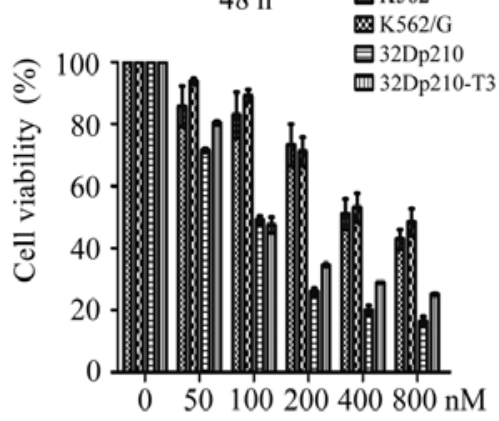

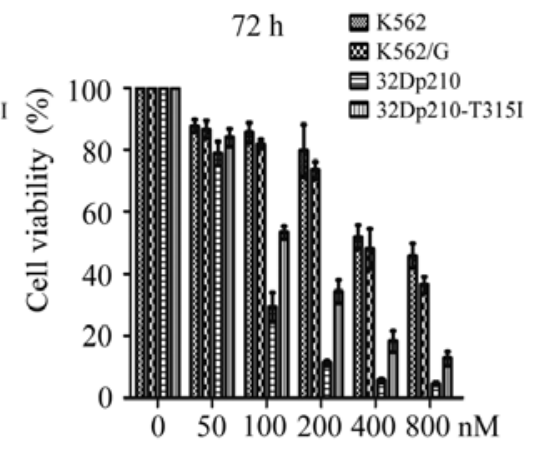

B

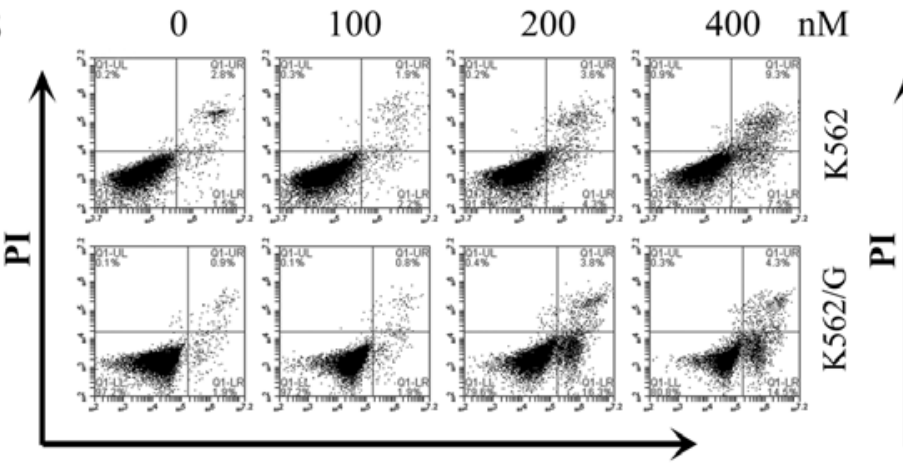

Annexin V-FITC

C

K562

$\mathrm{K} 562 / \mathrm{G}$

$0 \quad 100200400 \mathrm{nM}$

$0100200400 \mathrm{nM}$
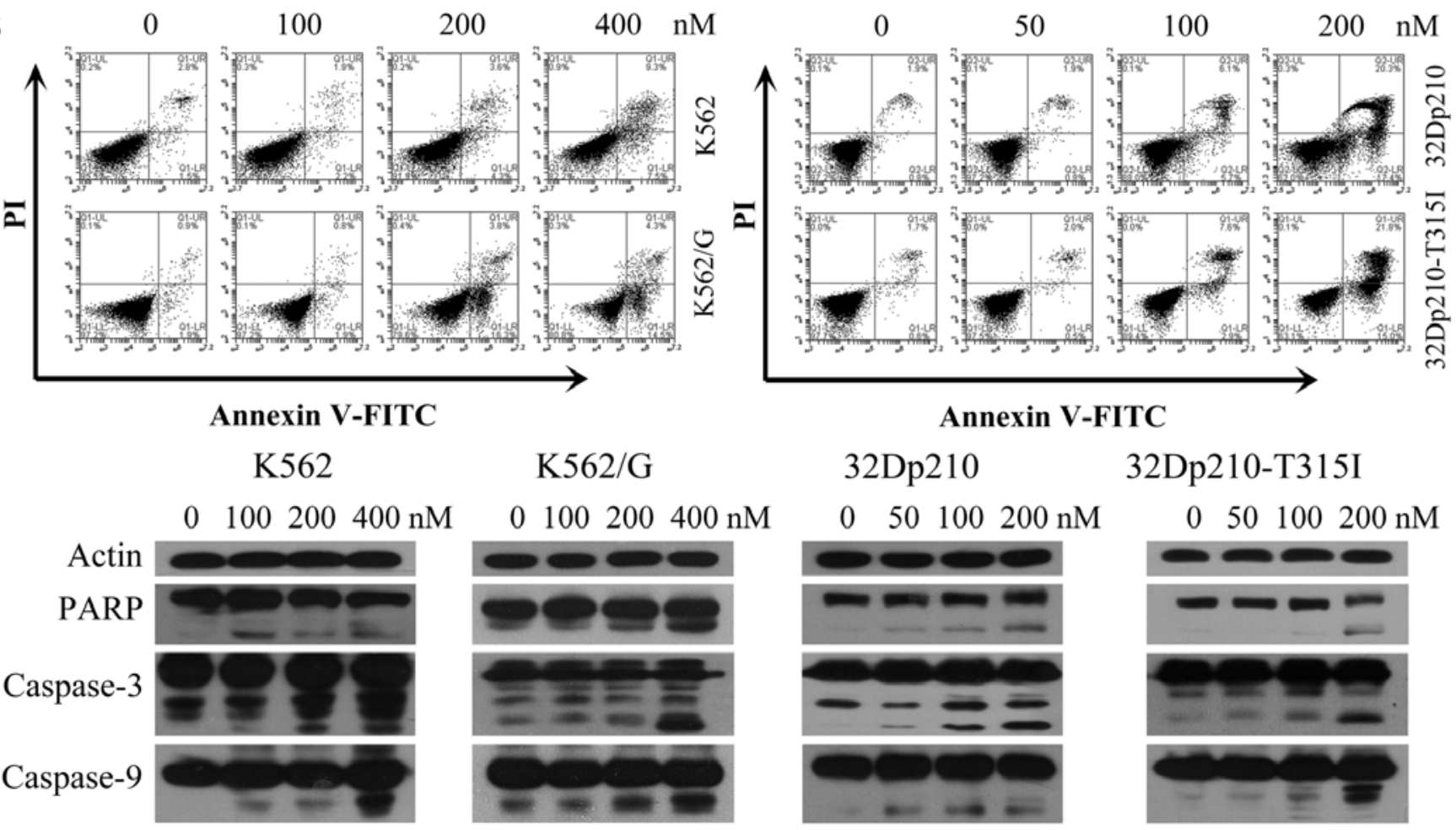

Annexin V-FITC

32Dp210

32Dp210-T315I

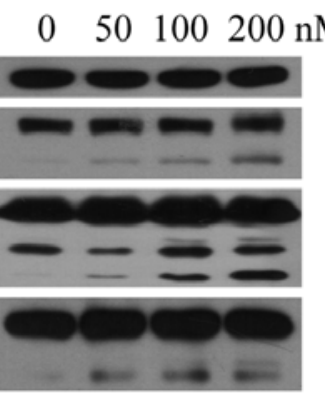

$\begin{array}{llll}0 & 50 & 100 & 200 \\ \end{array}$

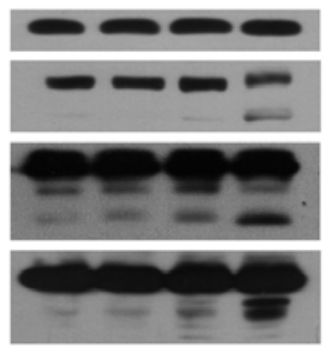

Figure 1. BIIB021 inhibits growth and induces apoptosis in CML cell lines. (A) Leukemic cell lines K562, K562/G, 32Dp210, and 32Dp210-T315I were cultured with or without different concentrations of BIIB021 for 24, 48 and $72 \mathrm{~h}$, respectively. Growth inhibition by BIIB021 was assessed by an MTT assay. Data are presented as the mean \pm SD of three independent experiments. (B) Cell lines were harvested at $48 \mathrm{~h}$ after treatment with various drug concentrations. Cells were stained by an Annexin V/PI-staining method and analyzed by flow cytometry. (C) CML cell lines were treated with BIIB021 (100, 200 and 400 nM) for $24 \mathrm{~h}$. Whole-cell lysates were subjected to western blotting to assess the cleavage of caspase-9, -3 and PARP.

BIIB021 inhibits $\beta$-catenin/c-Myc pathway in BCR-ABL positive cells. Since it has been shown that $\mathrm{Wnt} / \beta$-catenin signaling is required for leukemic stem cell maintenance in CML (26), and the tyrosine kinase activity of $\mathrm{BCR}-\mathrm{ABL}$ is required to phosphorylate $\beta$-catenin (27), experiments were performed to ascertain effects of BIIB021 on $\beta$-catenin signaling. Western blot analysis revealed that treatment with BIIB021 caused a significant reduction in levels of $\beta$-catenin and non-phospho (Active) $\beta$-catenin (Ser33/37/Thr41), together with a marked downregulation of c-Myc, a downstream molecule of $\beta$-catenin signaling (Fig. 4A). To determine the intracellular localization of $\beta$-catenin protein in untreated and BIIB021-treated K562 and 32Dp210-T315I cells, we obtained nuclear and cytoplasmic protein extracts. Compared with untreated control, the levels of $\beta$-catenin were significantly decreased in both nuclear and cytoplasmic extracts from BIIB021-treated cells (Fig. 4B). This effect was confirmed by confocal microscopy analysis (Fig. 4C).
BIIB021 induces Beclin-1-independent autophagy in CML cells. It was reported that Hsp90 inhibitor geldanamycin can induce autophagy (28). We then investigated whether BIIB021 could induce autophagy in K562 and 32Dp210-T315I cells. As shown in Fig. 5A, MDC fluorescence was observed in control and BIIB021-treated CML cells. However, BIIB021-treated cells displayed more frequent accumulation of MDC than control cells. Acridine orange staining of BIIB021-treated CML cells also showed significantly increased formation of acidic vesicles (Fig. 5B). Consistent with these data, western blot analysis showed that increased conversion of LC3-I to LC3-II, and decreased p62 (SQSTM1) protein levels, in a dose-dependent manner, were found in the BIIB021-treated cells (Fig. 5C and D). Unexpectedly, we found downregulation of Beclin-1, a key protein inducing autophagy, in the BIIB021treated cells (Fig. 5C and D). These experiments collectively demonstrated induction of autophagy by BIIB021, which may be via a Beclin-1-independent mechanism. 

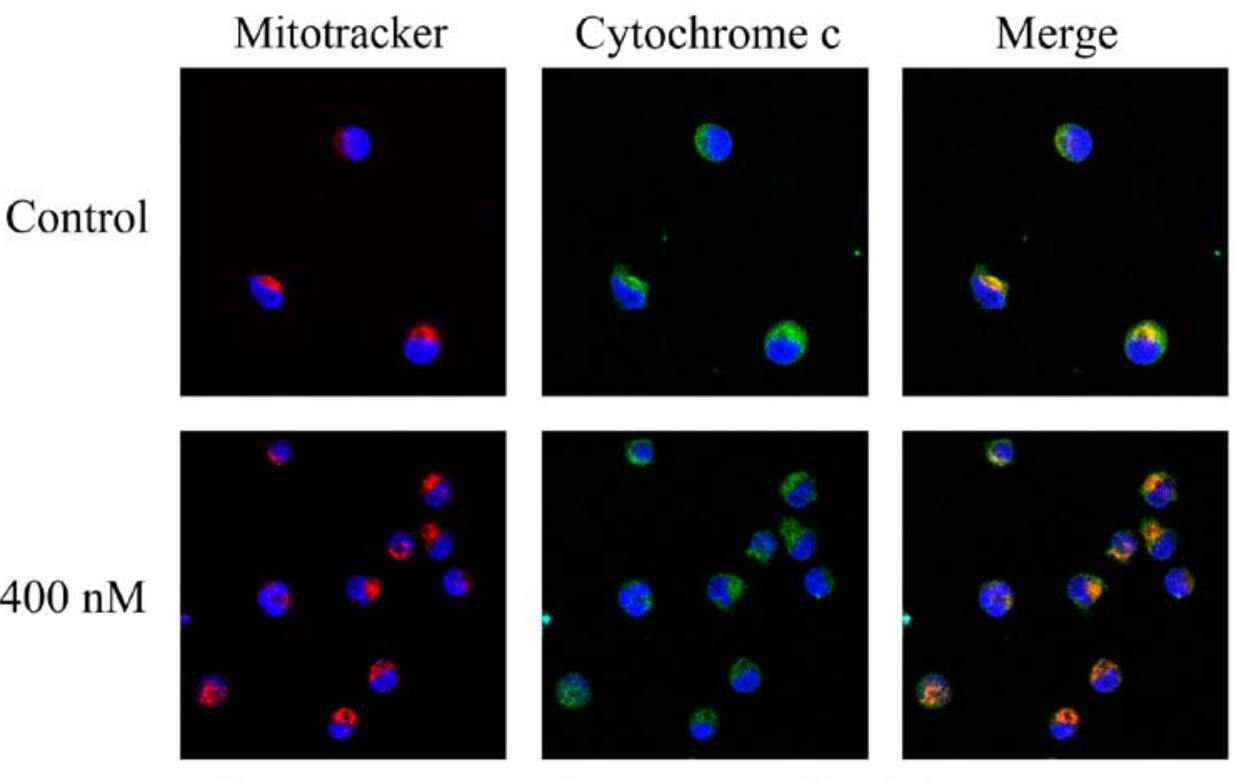

B

K562 K562/G

32Dp 210

32Dp210-T315I

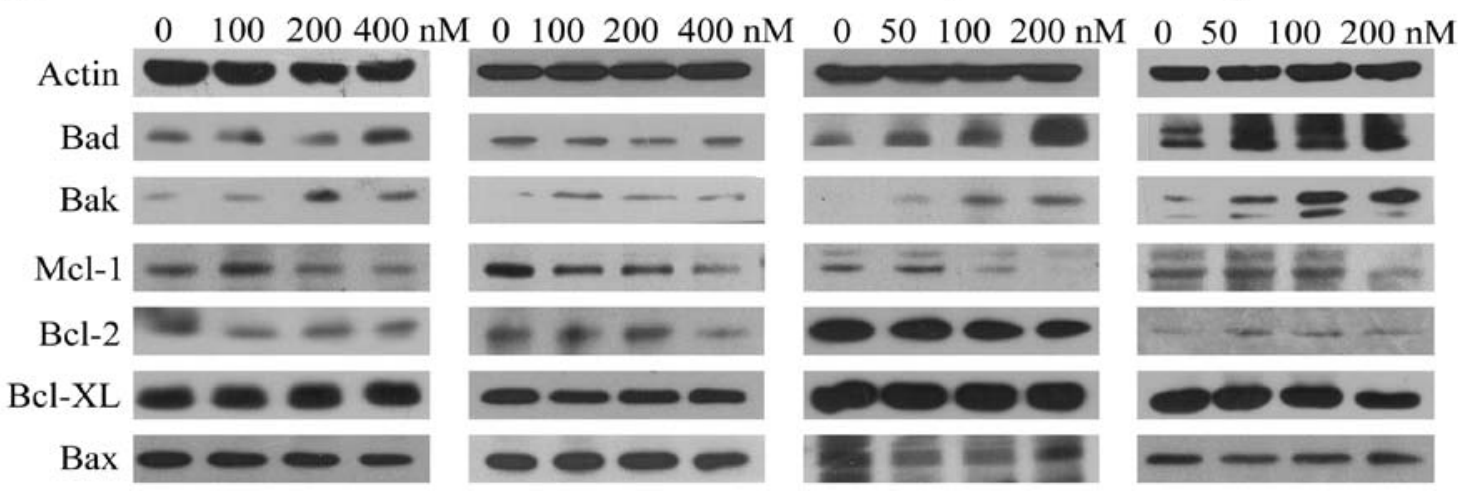

Figure 2. BIIB021 mediates mitochondrial dysfunction in CML cells. (A) Cell confocal microscopic images of cytochrome $c$ (green) and mitochondria (red) stained by MitoTracker were collected from K562 cells under treatment of $400 \mathrm{nM}$ BIIB021 for 24 h. Merged images show the co-localization of cytochrome $c$ and mitochondria (yellow). (B) After treatment with the indicated doses of BIIB021 for $24 \mathrm{~h}$, whole cell proteins extracted from CML cell lines were quantified and loaded. Western blotting was used to analyze the expression of Bad, Bak, Mcl-1, Bcl-2, Bcl-xL and Bax. Actin was used as a loading control. The results are representatives of three separate experiments.

We next examined alteration of mRFP-GFP-LC3 fluorescent signals by confocal microscopy (29) to analyze autophagic flux. An increase in number of acidic autophagolysosomes (red fluorescence) and non-acidic autophagolysosomes (yellow) was observed in BIIB021-treated 32Dp210-T315I cells (Fig. 5E). To further determine the autophagic flux into the lysosomal compartment, we analyzed LC3-II and p62 in cells co-treated with $\mathrm{Baf} \mathrm{A} 1$, an inhibitor of vacuolar $\mathrm{H}^{+}$ ATPase that leads to accumulation of autophagic vacuoles by blocking their fusion with lysosomes (Fig. 5F). The levels of LC3-II and p62 protein determined by immunodetection were increased in the presence of Baf A1, supporting the notion that BIIB021 causes activation of autophagy by promoting the synthesis of autophagosome and increasing autophagic flux. We further investigated whether BIIB021-induced autophagy acted as a cytoprotective mechanism. For this purpose, we inhibited autophagy in 32Dp210-T315I cells by using $2.5 \mathrm{mM}$ 3-MA, a specific inhibitor of autophagic sequestration, and analyzed the effects on the levels of LC3-II and p62, as well as BIIB021-induced cell death. As shown in Fig. 5G, inhibition of cellular proliferation by BIIB021 following 3-MA pretreatment was significantly higher than that in the absence of 3-MA $(\mathrm{P}<0.05)$. Western blot analysis indicated that 3-MA inhibited the conversion of LC3-I to LC3-II and reversed the reduction of p62 proteins. Furthermore, pretreatment of cells with 3-MA strongly increased the cleavage of caspase-3 and PARP induced by BIIB021 (Fig. 5H).

BIIB021-mediated caspase activation contributes to inhibition of Beclin-1 expression. Recent studies suggested that the activation of caspase at the onset of apoptosis could mediate cleavage of Beclin-1 and thereby inhibit Beclin-1-induced autophagy $(30,31)$. To investigate if BIIB021 causes inhibition of Beclin-1 in CML cells in association with the activation of caspase, we incubated K562 and 32Dp210-T315I cells with the broad caspase inhibitor z-VAD-fmk and BIIB021. As shown in Fig. 6A, pretreatment with z-VAD-fmk resulted in a partial reversal of inhibition of BIIB021, in parallel with an enhanced autophagy as evidenced by increased amount of LC3-II and decreased amount of p62. In contrast, BIIB021induced apoptosis was inhibited by z-VAD-fmk. Similar results were found in 32Dp210-T315I cells pretreated with 
A

K562 K562/G

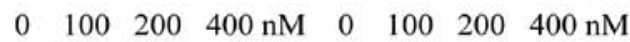

E $=-\ldots$

$\mathbf{B}$
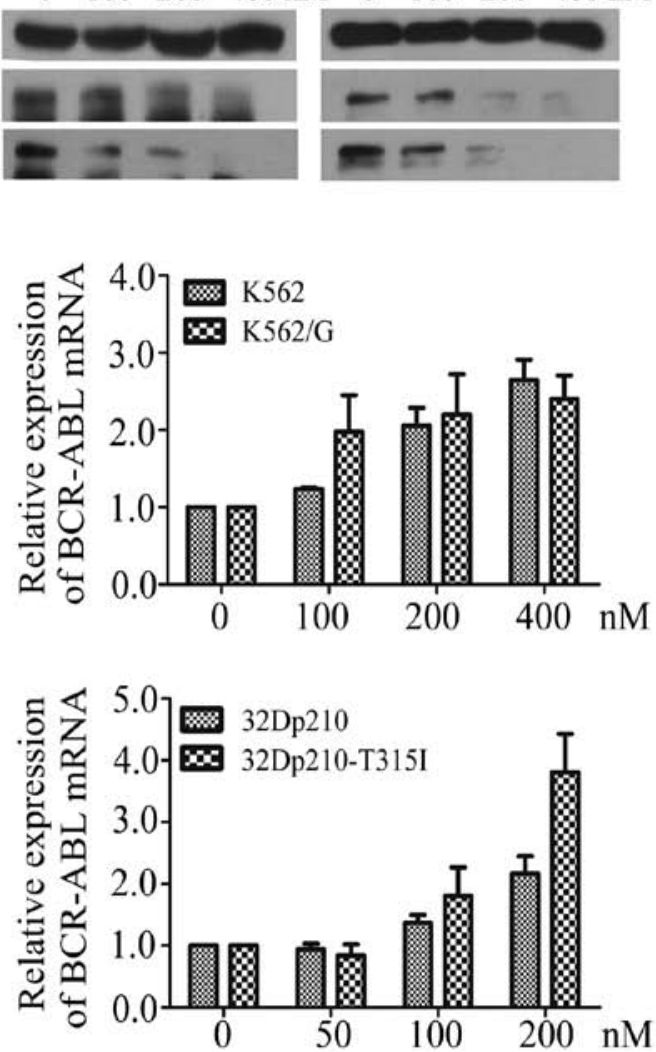

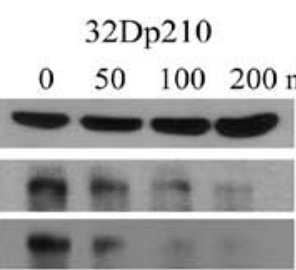

32Dp210-T315I

C

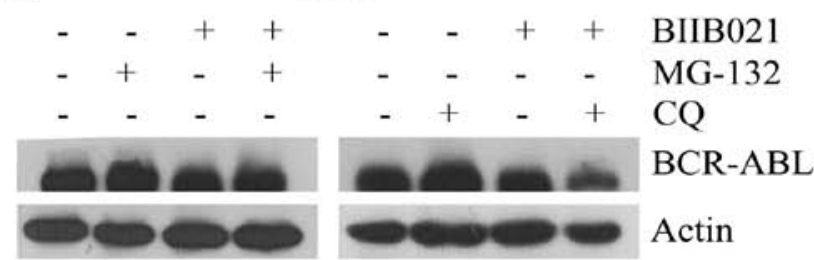

D 32Dp210-T315I

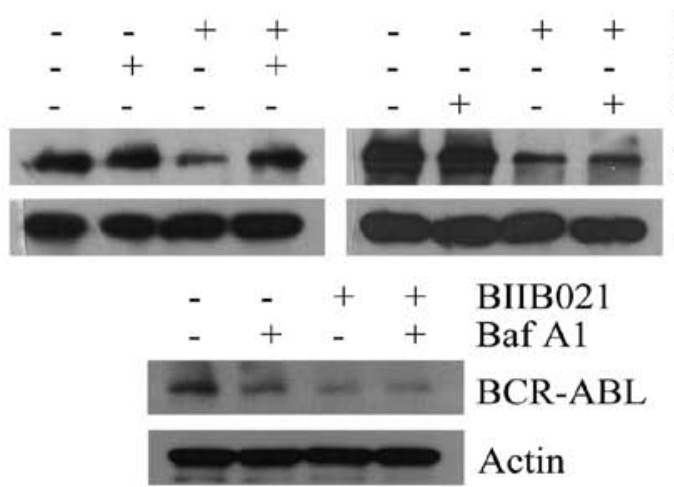

32Dp 210

32Dp210-T315I

$\mathrm{K} 562 / \mathrm{G}$

$\mathbf{E}$

K562

$50 \quad 100200 \mathrm{nM}$
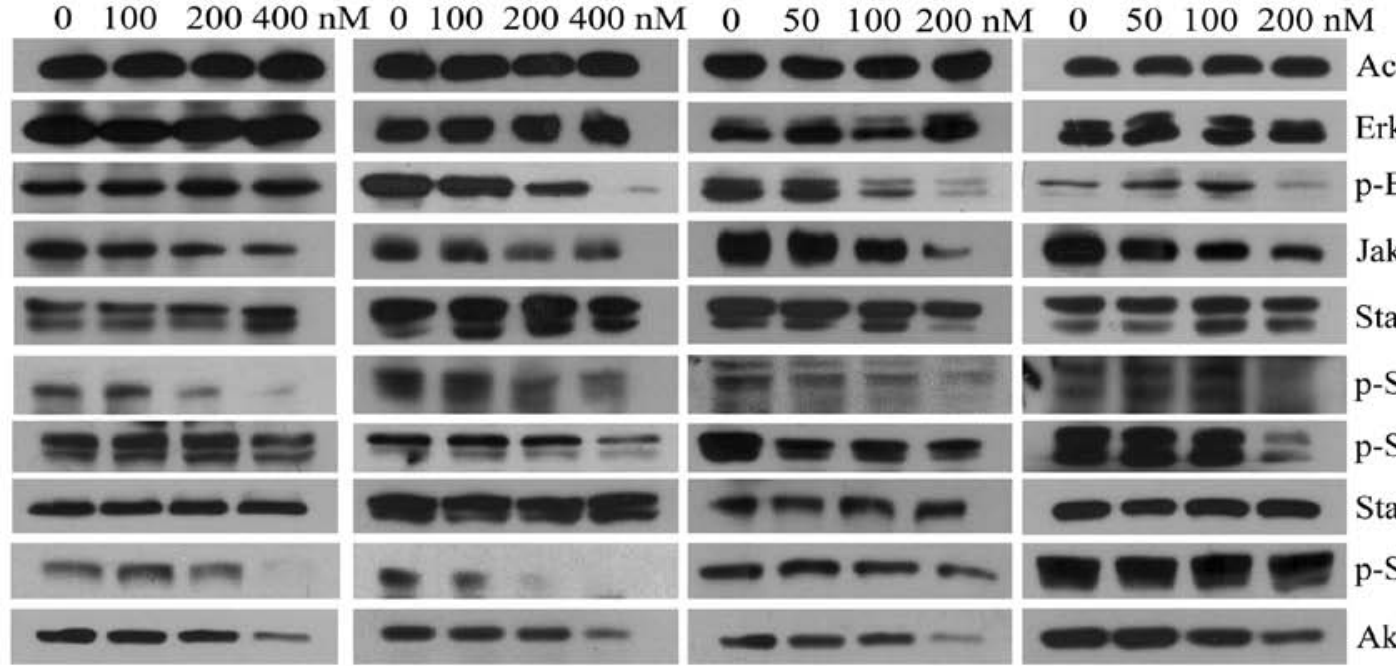

$\Leftrightarrow=20$ Actin

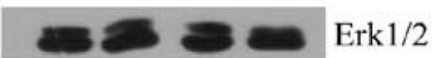

$--\mathrm{p}-\mathrm{Erk} 1 / 2 \mathrm{~T}^{202} / \mathrm{Y}^{204}$

$\mathrm{m}=\mathrm{Jak} 2$

$\underset{S}{2} \mathrm{Stat} 3$

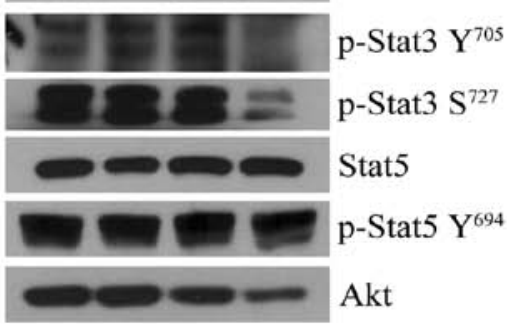

Figure 3. BIIB021 inhibits the expression of BCR-ABL and its downstream signaling mediators. (A) Four kinds of leukemic cell lines were treated with BIIB021 at the indicated doses for $24 \mathrm{~h}$. Whole-cell lysates were extracted to assess the levels of BCR-ABL and phosphorylated (p)-BCR-ABL (Tyr177).

(B) Leukemic cell lines were treated with BIIB021 at the indicated concentrations for $24 \mathrm{~h}$. The expression levels of mRNA were evaluated by real-time PCR. The relative changes in gene expression are shown compared to the untreated controls. (C) After pretreated with MG-132 (1.0 $\mu \mathrm{M})$, or with CQ (25 $\mu \mathrm{M})$ for $4 \mathrm{~h}, \mathrm{~K} 562$ cells were treated with BIIB021 for $20 \mathrm{~h}$. Whole-cell lysates were then prepared and analyzed for expression of BCR-ABL by western blotting. (D) 32Dp210-T315I cells were pretreated with MG-132, CQ, or with Baf A1 (25 nM) for $4 \mathrm{~h}$. Cell lysates were subjected to western blotting to determine expression of BCR-ABL. (E) After incubation of CML cell lines with the indicated concentrations of BIIB021, whole-cell lysates were analyzed for p-Erk1/2 (Thr202/Tyr204), total Erk1/2, Jak2, p-Stat3 (Tyr705 and Ser727), total Stat3, p-Stat5 (Tyr694), total Stat5 and Akt expression by western blot analysis.

a specific caspase-3 inhibitor z-DEVD-fmk (Fig. 6B), and in K562 cells where caspase-3 was knocked down by shRNA transfection (Fig. 6C).
BIIB021 induces autophagy by affecting Ulk1 and negatively regulating $m T O R$. Autophagy depends on the hierarchically ordered activity of autophagy-related (ATG) proteins which 


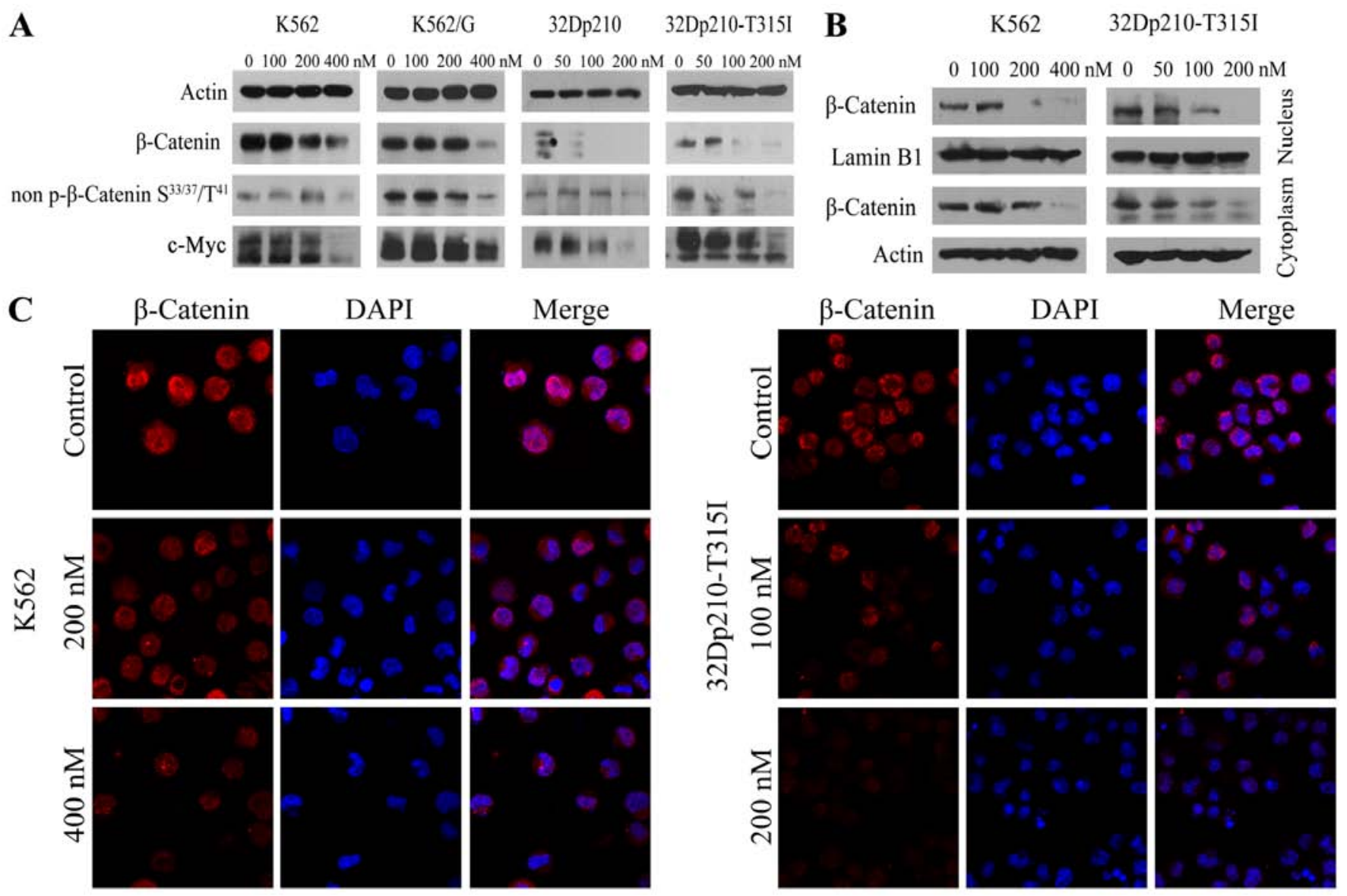

Figure 4. The effect of BIIB021 on $\beta$-catenin signaling. (A) All tested CML cell lines were incubated with BIIB021 at the indicated concentrations for $24 \mathrm{~h}$ and then analyzed for expression of $\beta$-catenin, non-phospho (active) $\beta$-catenin (Ser33/37/Thr41), and c-Myc by western blotting. (B) After treatment with BIIB021 for $24 \mathrm{~h}$, cells were collected, and then nuclear and cytoplasmic extracts were prepared to check the levels of $\beta$-catenin by western blotting. (C) K562 and 32Dp210-T315I cells were treated with BIIB021 at the indicated doses for $24 \mathrm{~h}$, and two-color confocal microscopy analysis of $\beta$-catenin protein (red) and nuclei (DAPI staining, blue) was performed.

were controlled by the main autophagy repressor, mTOR that prevents Ulk1 activation by phosphorylating Ulk1 at Ser757. In contrast, AMPK promotes autophagy by activating Ulk1 through phosphorylation of Ser317 and Ser777 $(32,33)$. Accordingly, we determined whether the mTOR-Ulk1 pathway or AMPK-Ulk1 pathway was involved in BIIB021-induced autophagy (Fig. 7A). There was no significant decrease in the amount of AMPK protein and phosphorylation of AMPK Thr172 in the BIIB021-treated cells. However, western blot analysis revealed that, along with downregulation of $\mathrm{Akt}$, BIIB021 dose-dependently inhibited the phosphorylation of mTOR Ser2448 and its downstream p70S6K Thr389 in K562 and 32Dp210-T315I cells. Importantly, treatment with BIIB021 also resulted in a significant decrease of phosphorylation of Ulk1 Ser757. Since Akt is upstream of mTOR, we then examined whether Akt activator IGF-1 attenuates BIIB021-induced inhibition of Akt, phosphorylation of mTOR Ser2448 and Ulk1 Ser757 in CML cells (Fig. 7B). Pretreatment with IGF-1 markedly restored the levels of Akt protein and phosphorylation of mTOR Ser2448, p70S6K Thr389 and Ulk1 Ser757. Moreover, IGF-1 pretreatment obviously decreased BIIB021-induced expression of LC3-II and downregulation of p62, indicating that inhibition of Akt-mTOR by BIIB021 reduced autophagy via reactivating Ulk1.

\section{Discussion}

Hsp90 has recently been considered as a promising target for therapeutic intervention in a variety of cancers (12). The biological activity of Hsp90 inhibitors towards CML has been demonstrated in vitro and in murine xenograft models (14-16,34,35). BIIB021 is the first oral, synthetic Hsp90 inhibitor to enter the clinic for treatment of solid tumors and lymphoma $(20,21)$. However, little is known regarding the potential activity of BIIB021 on CML. In this study, we investigate the potential antitumor effects of BIIB021 on imatinib-sensitive and -resistant CML cell lines as well as leukemic cells bearing T315I mutation. We found that BIIB021 effectively inhibited the proliferation of CML cells, and clearly indicated that by lowering BCR-ABL, BIIB021 induced release of cytochrome $c$, which promotes consequential activation of caspase-9, -3 and PARP, thereby inducing apoptosis. Additionally, BIIB021 treatment resulted in the accumulation of proapoptotic proteins Bad and Bak, which are involved in mitochondrial outer membrane permeabilization, a critical event responsible for caspase activation in the intrinsic pathway (36). These results are consistent with a previous report showing that novobiocin, a new Hsp90 inhibitor, induces the mitochondrial pathway of apoptosis in CML cells (15). 
A
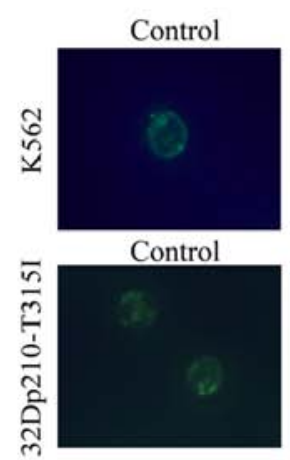

K562

C

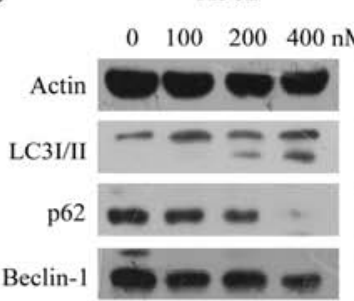

D

$32 \mathrm{Dp} 210$

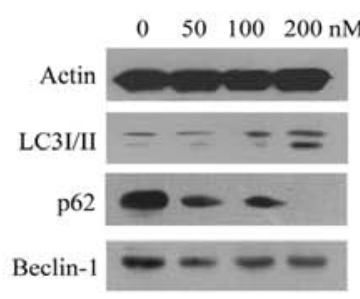

$\mathbf{E}$
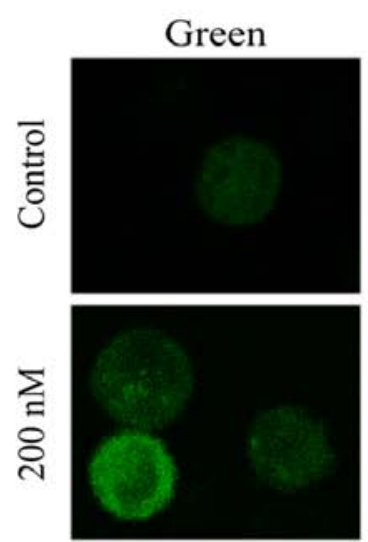

$400 \mathrm{nM}$

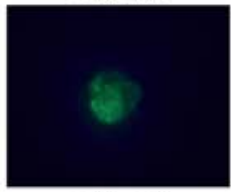

$200 \mathrm{nM}$

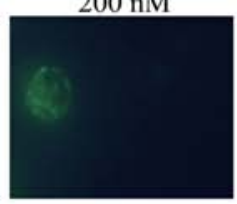

B

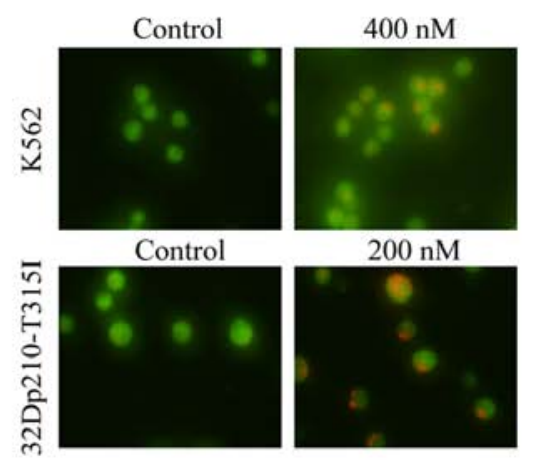

$\mathbf{F}$
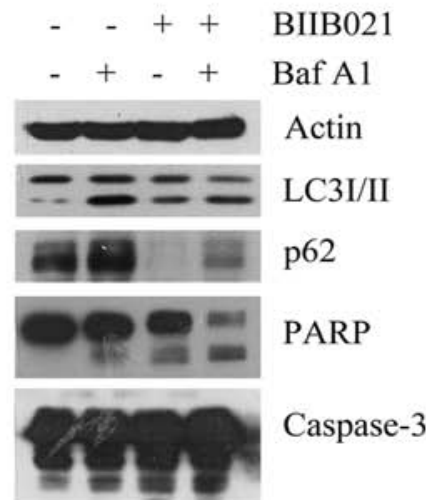

32Dp210-T315I
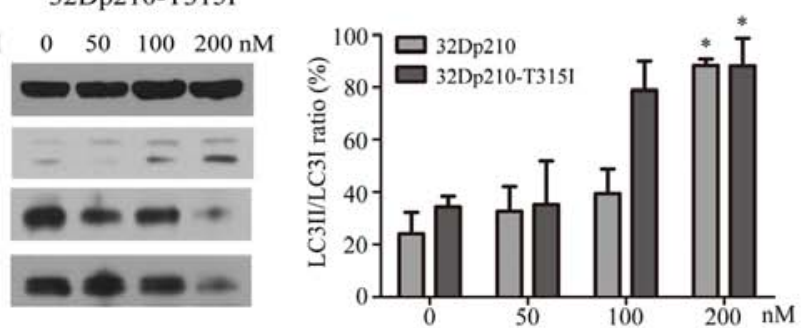

32Dp210-T315I
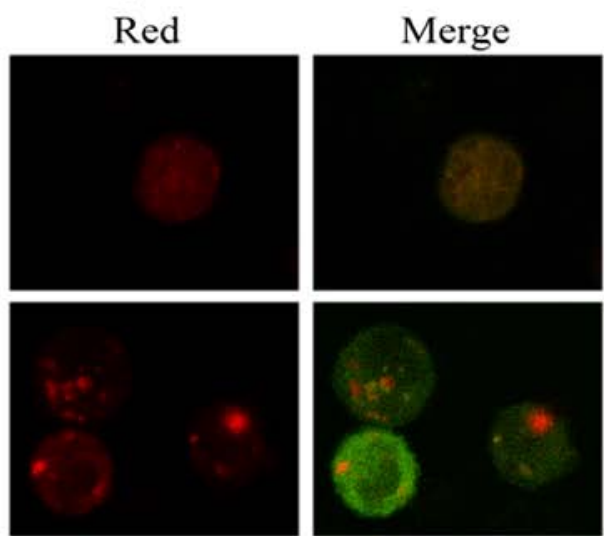

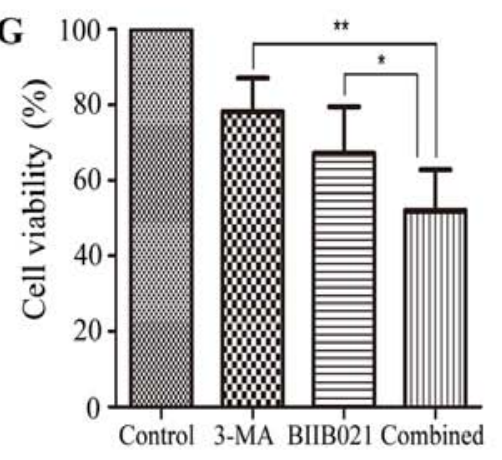

$\mathbf{H}$

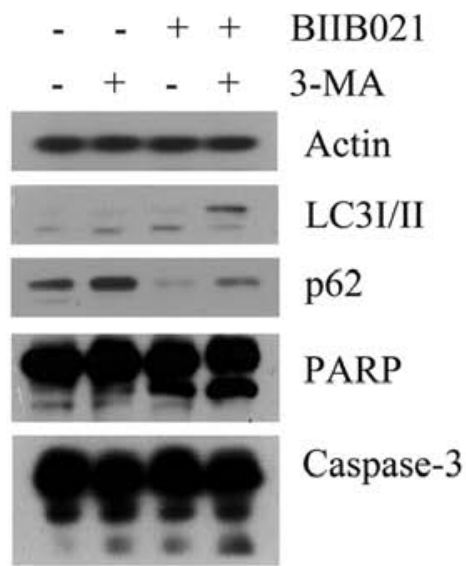

Figure 5. Induction of autophagy by BIIB021 in CML cells. (A) K562 and 32Dp210-T315I cells were treated with BIIB021 at the indicated doses for $48 \mathrm{~h}$. Then cells were stained with MDC $\left(0.1 \mathrm{mM} 37^{\circ} \mathrm{C}\right.$ for $\left.60 \mathrm{~min}\right)$ and observed under a fluorescence microscope. (B) After treatment with BIIB021 for $48 \mathrm{~h}$, cells were collected and stained with $\mathrm{AO}\left(1 \mu \mathrm{g} / \mathrm{ml} 37^{\circ} \mathrm{C}\right.$ for $\left.15 \mathrm{~min}\right)$. Fluorescence microscopy was used to take the images of cells. (C and D) CML cell lines were treated with the indicated concentrations of BIIB021 for $24 \mathrm{~h}$. Whole-cell lysates were extracted to evaluate the levels of LC3 conversion, p62 and Beclin-1. The LC3-II/LC3-I was calculated based on densitometry analysis of both bands. (E) 32Dp210-T315I cells were transfected with AdmRFP-GFP-LC3. Next, cells were incubated with BIIB021 (200 nM) for $48 \mathrm{~h}$ and examined by confocal microscopy. Green dots represent GFP-LC3 while red dots represent acidic autolysosomes. Yellow dots result from merged images and represent non-acidic autolysosomes. After pretreated with the autophagy inhibitors Baf A1 (20 nM) or 3-MA (2.5 mM), 32Dp210-T315I cells were incubated for $48 \mathrm{~h}$ with BIIB021 $(100 \mathrm{nM})$. Whole-cell lysates were used to detect the expression levels of LC3 conversion, p62, caspase-3 and PARP by western blot analysis (F and H). Cell viability was measured by MTT assay (G). Data are expressed as the mean \pm SD, and analyzed by Student's t-test. ${ }^{*} \mathrm{P}<0.05,{ }^{* *} \mathrm{P}<0.01$.

Degradation of BCR-ABL oncoproteins by either Hsp90 inhibitors via the proteasome pathway $(15,34)$ or arsenic and imatinib through the lysosome pathway $(37,38)$ in CML has been shown to overcome resistance to TKIs. This represents an alternative treatment strategy that does not rely solely on kinase domain inhibition. In this study, we show that treatment with BIIB021 caused a significant reduction in the levels of both total and phosphorylation of BCR-ABL protein in CML 
A

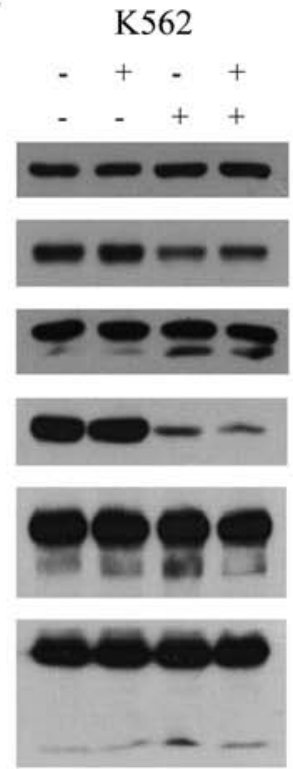

32Dp210-T315I

- + - + z-VAD-fmk

- $\quad+\quad+$ BIIB021
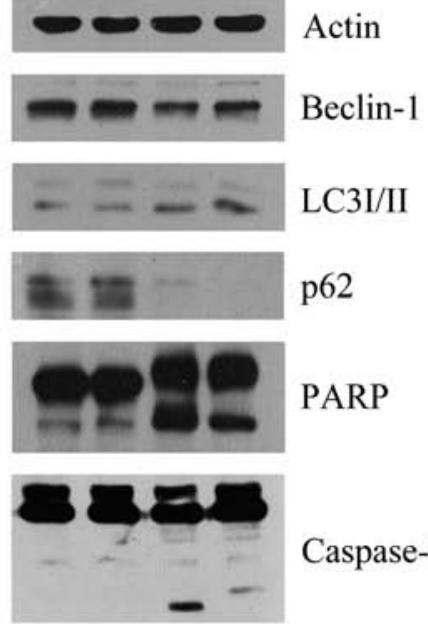

B 32Dp210-T315I

- + - + z-DEVD-fmk

$-\quad++$ BIIB021

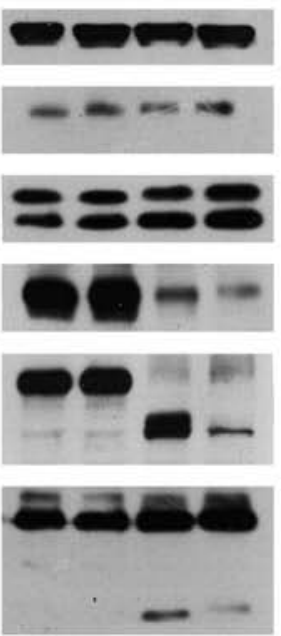

Caspase-3
C

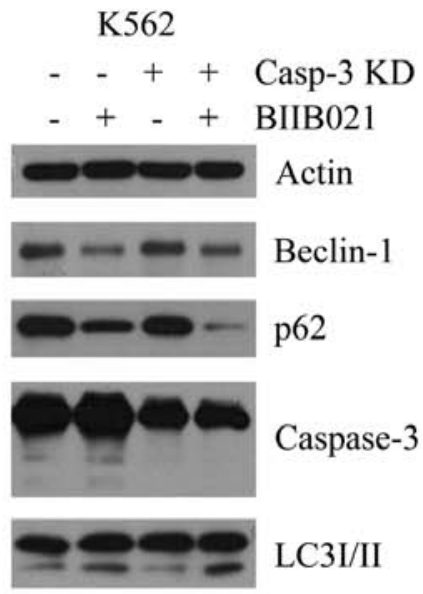

Figure 6. Caspase activation degrades Beclin-1. (A and B) After pretreatment with z-VAD-fmk ( $20 \mu \mathrm{M})$ or z-DEVD-fmk (20 $\mu \mathrm{M})$ for $1 \mathrm{~h}$, K562 cells were exposed to BIIB021 (400 nM) while 32Dp210-T315I cells were exposed to BIIB021 (200 nM) for $24 \mathrm{~h}$. Whole-cell lysates were subjected to western blot analysis to examine the expression of Beclin-1, LC3I/II, p62, PARP and caspase-3. (C) K562 cells were transfected with lentiviral vectors containing caspase-3 shRNA or control shRNA and selected in medium containing puromycin. Then cells were treated with BIIB021 (400 nM) for $24 \mathrm{~h}$. Beclin-1, p62 and LC3I/II levels of whole-cell lysates were detected by western blot analysis. Silencing of caspase-3 was also confirmed by western blot analysis.

\section{A}

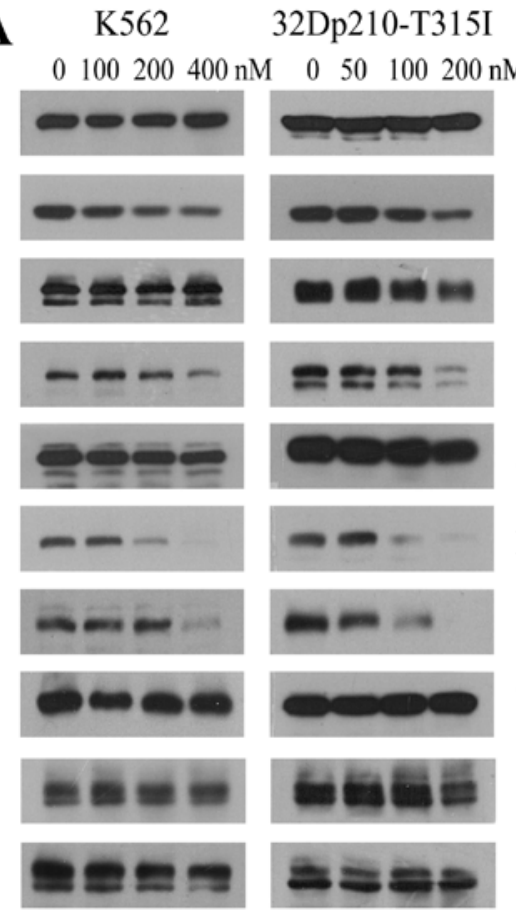
M

Actin

Akt

mTOR

p-mTOR S $\mathrm{S}^{248}$

p70S6K

p-p70S6K T ${ }^{389}$

Ulk1 S ${ }^{757}$

Ulk1

AMPK $\alpha$

$\mathrm{p}-\mathrm{AMPK} \alpha \mathrm{T}^{172}$
B 32Dp210-T315I
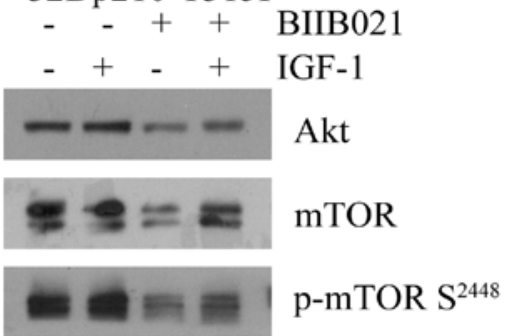

$=-m-570 S 6 \mathrm{~K}$
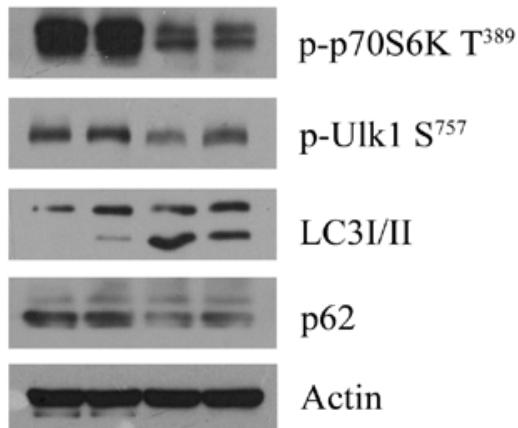

Figure 7. BIIB021 regulates the Akt-mTOR pathway to initiate autophagy. (A) K562 and 32Dp210-T315I cells were treated with BIIB021 at the indicated doses for $24 \mathrm{~h}$. Whole cells were lysed to evaluate the expression levels of Akt, total mTOR, p-mTOR (Ser2448), total p70S6K, p-p70S6K (Thr389), total Ulk1, p-Ulk1 (Ser757), AMPK $\alpha$, and p-AMPK $\alpha$ (Thr172) by western blot analysis. (B) After pretreated with IGF-1 (200 ng/ml) for $4 \mathrm{~h}, 32 \mathrm{Dp} 210-\mathrm{T} 315 \mathrm{I}$ cells were exposed to BIIB021 (200 nM) for $24 \mathrm{~h}$. Then, whole-cell lysates were extracted to analyze the protein levels of Akt, total mTOR, p-mTOR (Ser2448), total p70S6K, p-p70S6K (Thr389), p-Ulk1 (Ser757), LC3 conversion, and p62 by western blot analysis.

cells harboring wild-type BCR-ABL or BCR-ABL-T315I mutation, even though the levels of BCR-ABL mRNA expression did not differ from untreated control. Furthermore, inhibition of BCR-ABL could be partly reversed by the protea- some inhibitor MG-132, but not by the lysosome inhibitor CQ and Baf A1. These data suggest that proteasome pathway is involved in BIIB021-mediated degradation of BCR-ABL oncoproteins. On the contrary, imatinib can not eliminate 
the primitive BCR-ABL positive stem cells of CML although it has shown remarkable efficacy in the treatment of $\mathrm{CML}$ $(39,40)$. $\beta$-catenin, the central mediator of the $\mathrm{Wnt} / \beta$-catenin signaling, is involved in transcriptional regulation and chromatin modification, and plays an important role in survival/ self-renewal of dividing BCR-ABL positive stem/progenitors $(26,27,41)$. Deletion of $\beta$-catenin has been shown to reduce survival and self-renewal of CML quiescent stem cells and synergize with imatinib to abrogate CML stem cells $(26,41)$. These results demonstrate that BIIB021 dose-dependently decreased $\beta$-catenin expression and concomitantly decreased the levels of its downstream c-myc. Confocal microscopy analysis showed that BIIB021 was able to completely abolish the nuclear accumulation of $\beta$-catenin.

Treatments with antileukemic agents, including TKI, have been shown to induce cellular autophagy in CML $(37,38,42,43)$. In this respect, autophagy exerts cytoprotective $(42,43)$ or beneficial actions (autophagic cell death) (37). The molecular regulation of autophagy and potential efficacy of autophagy inhibition in CML have been reviewed in detail (44). In this study, we found that cells treated with BIIB021 showed pronounced autophagy evidenced by increased formation of AVOs and levels of LC3-II in cells. In order to investigate whether autophagy underlies cell death or protective response, we blocked autophagy by Baf A1 or 3-MA. Inhibition of autophagy significantly enhanced cell death in the BIIB021-treated CML cells, and this cell death depended on caspase activation, suggesting that a combination of BIIB021 and autophagy inhibitor could be beneficial for the treatment of CML. We also attempted to address the key question as to the signals delivered by BIIB021 that induce autophagy.Can et al (45) reported that Beclin-1, a critical regulator of autophagy initiation, is required for autophagy induction by imatinib. However, there was downregulation of Beclin-1 proteins in the cells treated with BIIB021. Recent evidence indicates that after initiating apoptosis by chemotherapy, Beclin-1 is cleaved by caspase and the N-terminal fragment of Beclin-1 can suppress autophagy (30,31). Our results demonstrated that the addition of the caspase inhibitor z-VAD-fmk and caspase-3 inhibition by z-DEVD-fmk or by siRNA partly abrogated BIIB021-induced downregulation of Beclin-1 and enhanced autophagy. Together, these data suggest that activation of caspase is associated with downregulation of Beclin-1, and BIIB021 triggers autophagy through Beclin-1 independent pathway.

It is well known that mTOR complex 1 (mTORC1) also acts as a negative regulator of autophagy by phophorylating and inhibiting Ulk1 (32,33). In acute myeloid leukemia cells, autophagy can be elicited for treatment with dual mTORC1 and mTORC2 inhibitors such as OSI-027, AZD-2014 and AZD8055 $(46,47)$. We showed for the first time that mTORUlk1 pathway might be involved in the initiation of autophagy because BIIB021 strongly inhibited phosphorylation of mTOR Ser2448, a marker for mTORC1 activity (48) which was accompanied by a decreased level of phosphor-Ulk1 Ser757. This effect may results in Ulk1 activation and induction of autophagy (33). Also, BIIB021 inhibited the level of Akt protein, an upstream molecule of mTOR. Furthermore, our results show that Akt activator IGF-1 not only rescued BIIB021-induced inhibition of Akt-mTOR pathway, but also suppressed the occurrence of autophagy. Collectively, present findings suggest that suppression of mTORC1 by BIIB021 contributed to the induction of autophagy.

In conclusion, these results suggest that BIIB021 stimulates a multifaceted effector mechanism, all parts of which are required for induction of cell death in both imatinib-sensitive and -resistant CML cells, including leukemic cells harboring T315I-mutant BCR-ABL. Also, BIIB021 significantly induces autophagy, which is Beclin-1 independent, but associated with downregulation of Akt-mTOR pathway and activation of Ulk1. Inhibition of autophagy enhances the sensitivity of CML cells to BIIB021. These data suggest the possibility of combining BIIB021 with autophagy inhibitors in a regimen that would optimize the antileukemic activity against CML.

\section{Acknowledgements}

This study was supported by National Natural Science Foundation of China (nos. 81370645, 81500110 and 81500111), Doctoral Fund of Ministry of Education of China (no. 20120101110010), Funds of Science Technology Department of Zhejiang Province (nos. 2012C13021-2 and 2014C33235), and Funds of the Hangzhou Science and Technology Bureau (no. 20120633B15).

\section{References}

1. Clark SS, Crist WM and Witte ON: Molecular pathogenesis of Ph-positive leukemias. Annu Rev Med 40: 113-122, 1989.

2. Danisz K and Blasiak J: Role of anti-apoptotic pathways activated by $\mathrm{BCR} / \mathrm{ABL}$ in the resistance of chronic myeloid leukemia cells to tyrosine kinase inhibitors. Acta Biochim Pol 60: 503-514, 2013.

3. Steelman LS, Pohnert SC, Shelton JG, Franklin RA, Bertrand FE and McCubrey JA: JAK/STAT, Raf/MEK/ERK, PI3K/Akt and $\mathrm{BCR}-\mathrm{ABL}$ in cell cycle progression and leukemogenesis. Leukemia 18: 189-218, 2004

4. Skorski T, Bellacosa A, Nieborowska-Skorska M, Majewski M, Martinez R, Choi JK, Trotta R, Wlodarski P, Perrotti D, Chan TO, et al: Transformation of hematopoietic cells by BCR/ABL requires activation of a PI-3k/Akt-dependent pathway. EMBO J 16: 6151-6161, 1997.

5. Lin TS, Mahajan S and Frank DA: STAT signaling in the pathogenesis and treatment of leukemias. Oncogene 19: 2496-2504, 2000.

6. Deininger M, Buchdunger E and Druker BJ: The development of imatinib as a therapeutic agent for chronic myeloid leukemia. Blood 105: 2640-2653, 2005.

7. Talpaz M, Shah NP, Kantarjian H, Donato N, Nicoll J, Paquette R, Cortes J, O'Brien S, Nicaise C, Bleickardt E, et al: Dasatinib in imatinib-resistant Philadelphia chromosome-positive leukemias. N Engl J Med 354: 2531-2541, 2006.

8. Kantarjian H, Giles F, Wunderle L, Bhalla K, O'Brien S, Wassmann B, Tanaka C, Manley P, Rae P, Mietlowski W, et al: Nilotinib in imatinib-resistant CML and Philadelphia chromosome-positive ALL. N Engl J Med 354: 2542-2551, 2006.

9. Hoy SM: Ponatinib: A review of its use in adults with chronic myeloid leukaemia or Philadelphia chromosome-positive acute lymphoblastic leukaemia. Drugs 74: 793-806, 2014.

10. Cortes JE, Kantarjian H, Shah NP, Bixby D, Mauro MJ, Flinn I, O'Hare T, Hu S, Narasimhan NI, Rivera VM, et al: Ponatinib in refractory Philadelphia chromosome-positive leukemias. N Engl J Med 367: 2075-2088, 2012.

11. Bishop SC, Burlison JA and Blagg BS: Hsp90: A novel target for the disruption of multiple signaling cascades. Curr Cancer Drug Targets 7: 369-388, 2007.

12. Isaacs JS, Xu W and Neckers L: Heat shock protein 90 as a molecular target for cancer therapeutics. Cancer Cell 3: 213-217, 2003.

13. Nimmanapalli R, O'Bryan E and Bhalla K: Geldanamycin and its analogue 17-allylamino-17-demethoxygeldanamycin lowers Bcr-Abl levels and induces apoptosis and differentiation of Bcr-Abl-positive human leukemic blasts. Cancer Res 61: 1799-1804, 2001 
14. Tao W, Chakraborty SN, Leng X, Ma H and Arlinghaus RB: HSP90 inhibitor AUY922 induces cell death by disruption of the Bcr-Abl, Jak2 and HSP90 signaling network complex in leukemia cells. Genes Cancer 6: 19-29, 2015.

15. Wu LX, Xu JH, Zhang KZ, Lin Q, Huang XW, Wen CX and Chen YZ: Disruption of the Bcr-Abl/Hsp90 protein complex: A possible mechanism to inhibit Bcr-Abl-positive human leukemic blasts by novobiocin. Leukemia 22: 1402-1409, 2008.

16. Tong WG, Estrov Z, Wang Y, O'Brien S, Faderl S, Harris DM, Van Pham Q, Hazan-Halevy I, Liu Z, Koch P, et al: The synthetic heat shock protein 90 (Hsp90) inhibitor EC141 induces degradation of Bcr-Abl p190 protein and apoptosis of $\mathrm{Ph}$-positive acute lymphoblastic leukemia cells. Invest New Drugs 29: 1206-1212, 2011.

17. Lundgren $\mathrm{K}$, Zhang H, Brekken J, Huser N, Powell RE, Timple $\mathrm{N}$ Busch DJ, Neely L, Sensintaffar JL, Yang YC, et al: BIIB021, an orally available, fully synthetic small-molecule inhibitor of the heat shock protein Hsp90. Mol Cancer Ther 8: 921-929, 2009.

18. Zhang H, Neely L, Lundgren K, Yang YC, Lough R, Timple N and Burrows F: BIIB021, a synthetic Hsp90 inhibitor, has broad application against tumors with acquired multidrug resistance. Int J Cancer 126: 1226-1234, 2010.

19. Chen W, Sin SH, Wen KW, Damania B and Dittmer DP: Hsp90 inhibitors are efficacious against Kaposi Sarcoma by enhancing the degradation of the essential viral gene LANA, of the viral co-receptor EphA2 as well as other client proteins. PLoS Pathog 8: e1003048, 2012

20. Suzuki M, Takeda $T$, Nakagawa $H$, Iwata $S$, Watanabe $T$, Siddiquey MN, Goshima F, Murata T, Kawada J, Ito Y, et al: The heat shock protein 90 inhibitor BIIB021 suppresses the growth of $\mathrm{T}$ and natural killer cell lymphomas. Front Microbiol 6: 280 , 2015.

21. Saif MW, Takimoto C, Mita M, Banerji U, Lamanna N, Castro J, O'Brien S, Stogard C and Von Hoff D: A phase 1, dose-escalation, pharmacokinetic and pharmacodynamic study of BIIB021 administered orally in patients with advanced solid tumors. Clin Cancer Res 20: 445-455, 2014.

22. Dickson MA, Okuno SH, Keohan ML, Maki RG, D'Adamo DR, Akhurst TJ, Antonescu CR and Schwartz GK: Phase II study of the HSP90-inhibitor BIIB021 in gastrointestinal stromal tumors. Ann Oncol 24: 252-257, 2013.

23. Lin S, Li J, Zhou W, Qian W, Wang B and Chen Z: BIIB021, an Hsp90 inhibitor, effectively kills a myelodysplastic syndrome cell line via the activation of caspases and inhibition of PI3K/Akt and NF- $\kappa B$ pathway proteins. Exp Ther Med 7: 1539-1544, 2014

24. Li M, Zhang X, Zhou WJ, Chen YH, Liu H, Liu L, Yang CM and Qan WB: Hsp90 inhibitor BIIB021 enhances triptolide-induced apoptosis of human T-cell acute lymphoblastic leukemia cells in vitro mainly by disrupting p53-MDM2 balance. Acta Pharmacol Sin 34: 1545-1553, 2013.

25. Qian W, Liu J, Jin J, Ni W and Xu W: Arsenic trioxide induces not only apoptosis but also autophagic cell death in leukemia cell lines via up-regulation of Beclin-1. Leuk Res 31: 329-339, 2007.

26. Heidel FH, Bullinger L, Feng Z, Wang Z, Neff TA, Stein L, Kalaitzidis D, Lane SW and Armstrong SA: Genetic and pharmacologic inhibition of $\beta$-catenin targets imatinib-resistant leukemia stem cells in CML. Cell Stem Cell 10: 412-424, 2012.

27. Coluccia AM, Vacca A, Duñach M, Mologni L, Redaelli S, Bustos VH, Benati D, Pinna LA and Gambacorti-Passerini C: Bcr-Abl stabilizes beta-catenin in chronic myeloid leukemia through its tyrosine phosphorylation. EMBO J 26: 1456-1466, 2007.

28. Mori M, Hitora T, Nakamura O, Yamagami Y, Horie R, Nishimura $\mathrm{H}$ and Yamamoto T: Hsp90 inhibitor induces autophagy and apoptosis in osteosarcoma cells. Int J Oncol 46: 47-54, 2015.

29. Del Bufalo D, Desideri M, De Luca T, Di Martile M, Gabellini C, Monica V, Busso S, Eramo A, De Maria R, Milella M, et al: Histone deacetylase inhibition synergistically enhances pemetrexed cytotoxicity through induction of apoptosis and autophagy in non-small cell lung cancer. Mol Cancer 13: 230, 2014.

30. Li H, Wang P, Sun Q, Ding WX, Yin XM, Sobol RW, Stolz DB, Yu J and Zhang L: Following cytochrome $c$ release, autophagy is inhibited during chemotherapy-induced apoptosis by caspase 8-mediated cleavage of Beclin 1. Cancer Res 71: 3625-3634, 2011.
31. Wirawan E, Vande Walle L, Kersse K, Cornelis S, Claerhout S, Vanoverberghe I, Roelandt R, De Rycke R, Verspurten J, Declercq W, et al: Caspase-mediated cleavage of Beclin-1 inactivates Beclin-1-induced autophagy and enhances apoptosis by promoting the release of proapoptotic factors from mitochondria. Cell Death Dis 1: e18, 2010.

32. Yang Z and Klionsky DJ: Mammalian autophagy: Core molecular machinery and signaling regulation. Curr Opin Cell Biol 22: 124-131, 2010.

33. Kim J, Kundu M, Viollet B and Guan KL: AMPK and mTOR regulate autophagy through direct phosphorylation of Ulk1. Nat Cell Biol 13: 132-141, 2011.

34. Peng C, Brain J, Hu Y, Goodrich A, Kong L, Grayzel D, Pak R, Read M and Li S: Inhibition of heat shock protein 90 prolongs survival of mice with BCR-ABL-T315I-induced leukemia and suppresses leukemic stem cells. Blood 110: 678-685, 2007.

35. Barnes DJ, De S, van Hensbergen P, Moravcsik E and Melo JV: Different target range and cytotoxic specificity of adaphostin and 17-allylamino-17-demethoxygeldanamycin in imatinib-resistant and sensitive cell lines. Leukemia 21: 421-426, 2007.

36. Green DR and Kroemer G: Pharmacological manipulation of cell death: Clinical applications in sight? J Clin Invest 115: 2610-2617, 2005.

37. Goussetis DJ, Gounaris E, Wu EJ, Vakana E, Sharma B, Bogyo M, Altman JK and Platanias LC: Autophagic degradation of the BCR-ABL oncoprotein and generation of antileukemic responses by arsenic trioxide. Blood 120: 3555-3562, 2012.

38. Elzinga BM, Nyhan MJ, Crowley LC, O'Donovan TR, Cahill MR and McKenna SL: Induction of autophagy by Imatinib sequesters $\mathrm{Bcr}-\mathrm{Abl}$ in autophagosomes and down-regulates Bcr-Abl protein. Am J Hematol 88: 455-462, 2013.

39. Graham SM, Jørgensen HG, Allan E, Pearson C, Alcorn MJ, Richmond L and Holyoake TL: Primitive, quiescent, Philadelphiapositive stem cells from patients with chronic myeloid leukemia are insensitive to STI571 in vitro. Blood 99: 319-325, 2002.

40. Bhatia R, Holtz M, Niu N, Gray R, Snyder DS, Sawyers CL, Arber DA, Slovak ML and Forman SJ: Persistence of malignant hematopoietic progenitors in chronic myelogenous leukemia patients in complete cytogenetic remission following imatinib mesylate treatment. Blood 101: 4701-4707, 2003

41. Neviani P, Harb JG, Oaks JJ, Santhanam R, Walker CJ, Ellis JJ, Ferenchak G, Dorrance AM, Paisie CA, Eiring AM, et al: PP2A-activating drugs selectively eradicate TKI-resistant chronic myeloid leukemic stem cells. J Clin Invest 123: 4144 4157,2013

42. Tong Y, Liu YY, You LS and Qian WB: Perifosine induces protective autophagy and upregulation of ATG5 in human chronic myelogenous leukemia cells in vitro. Acta Pharmacol Sin 33: 542-550, 2012

43. Kamitsuji Y, Kuroda J, Kimura S, Toyokuni S, Watanabe K, Ashihara E, Tanaka H, Yui Y, Watanabe M, Matsubara H, et al: The Bcr-Abl kinase inhibitor INNO-406 induces autophagy and different modes of cell death execution in Bcr-Abl-positive leukemias. Cell Death Differ 15: 1712-1722, 2008.

44. Helgason GV, Karvela M and Holyoake TL: Kill one bird with two stones: Potential efficacy of BCR-ABL and autophagy inhibition in CML. Blood 118: 2035-2043, 2011.

45. Can G, Ekiz HA and Baran Y: Imatinib induces autophagy through BECLIN-1 and ATG5 genes in chronic myeloid leukemia cells. Hematology 16: 95-99, 2011.

46. Willems L, Chapuis N, Puissant A, Maciel TT, Green AS, Jacque N, Vignon C, Park S, Guichard S, Herault O, et al: The dual mTORC1 and mTORC2 inhibitor AZD8055 has anti-tumor activity in acute myeloid leukemia. Leukemia 26: 1195-1202, 2012.

47. Altman JK, Szilard A, Goussetis DJ, Sassano A, Colamonici M, Gounaris E, Frankfurt O, Giles FJ, Eklund EA, Beauchamp EM, et al: Autophagy is a survival mechanism of acute myelogenous leukemia precursors during dual mTORC2/mTORC1 targeting. Clin Cancer Res 20: 2400-2409, 2014

48. Park S, Chapuis N, Tamburini J, Bardet V, Cornillet-Lefebvre P, Willems L, Green A, Mayeux P, Lacombe C and Bouscary D: Role of the PI3K/AKT and mTOR signaling pathways in acute myeloid leukemia. Haematologica 95: 819-828, 2010. 